\title{
Evaluation of $F$ wave and split hand index in patients with amyotrophic lateral sclerosis
}

\author{
Noor H. Mohammed ${ }^{1}$, Farqad B. Hamdan ${ }^{2,3^{*}}$ (D) and Akram M. Al-Mahdawi ${ }^{4}$ (D)
}

\begin{abstract}
Background: Amyotrophic lateral sclerosis (ALS) is characterized by gradual disturbance of both upper and lower motor neurons (LMN). In ALS, muscle wasting favors the abductor pollicis brevis (APB) and first dorsal interosseous $(\mathrm{FDI})$, with relative preservation of abductor digiti minimi (ADM).

Objectives: To interpret $F$ wave changes in the context of upper and LMN dysfunction and the differences in dysfunction between spinal motoneurons innervating the APB and ADM.

Patients and methods: Forty-four subjects were studied (22 patients with ALS and 22 controls). F wave was elicited by 50 electrical stimuli from the median and ulnar nerves, and the split hand index (SHI) was measured.

Results: $\mathrm{F}$ latency mean, median, and maximum and $\mathrm{F}$ amplitude mean, median, and maximum F/M amplitude ratio were increased in patients with versus those without pyramidal signs. Limb-onset ALS patients showed the biggest reduction in SHI. The APB muscle of patients with no detectable wasting and upper MN (UMN) signs showed reduced $\mathrm{F}$ wave persistence, mean $\mathrm{F}$ wave latency and amplitudes, increased index repeater neuron and index $\mathrm{F}$ repeater, and mean $\mathrm{F} / \mathrm{M}$ amplitude ratio.

Conclusion: There is enhanced segmental motoneuronal excitability following UMN dysfunctions. SHI appears to be a diagnostic biomarker for ALS. Abnormal F parameters recorded from APB muscle can distinct patients with ALS from the normal controls to a greater extent than do the APB/ADM and FDI/ADM compound muscle action potential amplitude ratios.
\end{abstract}

Keywords: ALS, F wave, Split hand index

\section{Introduction}

In amyotrophic lateral sclerosis (ALS), hand muscle wasting preferentially affects the abductor pollicis brevis (APB) and first dorsal interosseous (FDI) muscles, with the relative conservation of the abductor digiti minimi (ADM) muscle [1, 2], although they are all innervated through the C8 and T1 spinal segments [3].

\footnotetext{
* Correspondence: Farqadbhamdan@colmed-alnahrain.edu.iq; farqadbhamdan@yahoo.com

${ }^{2}$ Department of Physiology, College of Medicine, Al-Nahrain University, Baghdad, Iraq

${ }^{3}$ Neurophysiology Unit, Al-Immamain Al-Kadhimiyain Medical City, Al-Kadhimiya, St. 60, Baghdad, Iraq

Full list of author information is available at the end of the article
}

This unique pattern of dissociated atrophy of the intrinsic hand muscles is termed the "split hand syndrome" [2, 4]. The split hand index (SHI), which quantifies the split hand phenomenon, is derived by multiplying the compound muscle action potential (CMAP) amplitude recorded over the thenar complex muscles (APB and FDI) and dividing this product by the CMAP amplitude recorded over the hypothenar muscles (ADM) [5].

The pathophysiology underlying the development of this split-hand has not been elucidated, yet central cortical hyperexcitability and peripheral axonal excitability mechanisms have been proposed $[3,6]$.

\section{Springer Open}

(c) The Author(s). 2020 Open Access This article is licensed under a Creative Commons Attribution 4.0 International License, which permits use, sharing, adaptation, distribution and reproduction in any medium or format, as long as you give appropriate credit to the original author(s) and the source, provide a link to the Creative Commons licence, and indicate if changes were made. The images or other third party material in this article are included in the article's Creative Commons licence, unless indicated otherwise in a credit line to the material. If material is not included in the article's Creative Commons licence and your intended use is not permitted by statutory regulation or exceeds the permitted use, you will need to obtain permission directly from the copyright holder. To view a copy of this licence, visit http://creativecommons.org/licenses/by/4.0/. 
F waves are low amplitude responses produced by antidromic activation ("backfiring") of motoneurons and reflect discharge of one to several motor units [7]. Therefore, they are affected by the normality or abnormality of the entire course of a motor nerve as well as by integrated central effects at the level of the motoneuron [8].

F waves may serve as an objective measure of pathophysiological changes in segmental motoneuronal excitability [9]. It can assess the inhibitory activity of the spinal interneuronal circuits also which might be among the earliest affected in ALS [10].

The present study aims to use $\mathrm{F}$ waves to investigate the pathophysiological changes in segmental motoneuronal excitability, interpret these $\mathrm{F}$ wave abnormalities in the context of upper and lower motor neuron (LMN) dysfunction, and to examine the differences in dysfunction between spinal motoneurons innervating the APB and ADM in ALS disease.

\section{Methods}

A case-control study was carried out at the departments of Neurology and Neurophysiology at Baghdad Teaching Hospital for the period from January 2018 till November 2019. The study was approved by the Iraqi Council for Medical Specialization (decision No. 1257; date 20 March 2019). All the participants were notified about the technique and aim of the study, and informed consent was obtained from them.

Twenty-two patients (11 males and 11 females) referred from a senior neurologist with definite and probable ALS according to the revised El Escorial criteria [11] aged 28 to 70 years (mean of 54.5 years) and mean disease duration from symptom onset was 15.3 months (range 6-24 months) were studied.

Patients with cervical myelopathy, pseudobulbar palsy of vascular origin, carpal or cubital tunnel syndrome based on clinical examination and nerve conduction studies (NCS), diabetes mellitus, alcoholism, and other systemic or neurological diseases, and those on riluzole, edaravone, or any antispasticity drugs were excluded from the study.

Another twenty-two age- and gender-matched (11 females and 11 males) with a mean age of 52.5 years serve as the control group.

Clinical neurological examination was done to look for the site of disease onset whether started in the upper limb, lower limb, or in the bulbar region. Upper motor neuron (UMN) signs in the upper limbs were checked for by the presence of increased muscle tone, clonus, increased tendon reflexes, or positive Hoffman signs [12]. Also, the ALS functional rating scale (ALSFRS) was used to determine patients' assessment of their capability and independence in 12 functional activities [13].
Furthermore, muscle power was tested from the upper and lower extremities against the examiner's resistance and grading the patient's strength on a 0 to 5 scale according to the Medical Research Council (MRC) scale [14].

Neurophysiologic testing was done using EMG/EP machine (serial no. GH17H9NW315431 B, model 1715, code GH17ESSM/EDC, Micromed, Italy). The room temperature was roughly maintained at $25-28^{\circ} \mathrm{C}$ during the test procedures, and skin temperature between 32 and $34^{\circ} \mathrm{C}$ was ensured using a skin thermometer.

The sensory nerve conduction study (SNCS) of median, ulnar, and sural nerves and the motor nerve conduction study (MNCS) of median, ulnar, tibial, and peroneal were performed according to the method of Preston and Shapiro [15] to check for any pathology other than ALS. The CMAP amplitude, distal motor latency (DML), MNCV, APB/ADM, and FDI/ADM CMAP amplitude ratio were measured.

Needle electromyographic activity of cranio-bulbar (genioglossus, masseter, and/or frontalis), cervical (FDI, brachioradialis, deltoid), thoracic (thoracic paraspinal at the midthoracic region, three levels), and lumbosacral regions (tibialis anterior, gastrocnemius, vastus medialis or lateralis) was studied, and twenty motor units were analyzed.

In all subjects, the ulnar and median nerves were bilaterally tested. A total of 50 stimuli were considered appropriate to explore the full potential of $\mathrm{F}$ waves. Only those deflections which had an amplitude of at least $40 \mu \mathrm{V}$ were accepted as $\mathrm{F}$ responses to differentiate them from background noise.

The minimum, mean, and maximum $\mathrm{F}$ wave latencies; $\mathrm{F}$ wave chronodispersion; $\mathrm{F}$ wave persistence; mean, median and maximum $\mathrm{F}$ wave amplitudes; mean, median, and maximum $\mathrm{F} / \mathrm{M}$ amplitude ratios; $\mathrm{F}$ wave duration; $\mathrm{F}$ wave $\mathrm{CV}$; number of repeater $\mathrm{F}$ waves; and giant $\mathrm{F}$ waves (amplitude of $1.2 \mathrm{mV}$ ) were assessed.

To study the differences in dysfunction between spinal motoneurons innervating the thenar and hypothenar muscles in ALS, we record F waves of the median and ulnar nerves with surface electrodes over the APB and ADM muscles. Moreover, to test for split hand, we measure baseline-to-peak CMAP amplitudes over the $\mathrm{APB}, \mathrm{FDI}$, and $\mathrm{ADM}$ muscles (APB/ADM ratio and FDI/ ADM ratio). To calculate the SHI is by multiplying the CMAP amplitude recorded over the APB and FDI muscles, and dividing this product by the CMAP amplitude recorded over the $\mathrm{ADM}$ muscle, as follows: $\mathrm{SHI}=\mathrm{APB}$ (CMAP) $\times$ FDI $($ CMAP)/ADM CMAP.

\section{Statistical analysis}

Microsoft Excel 2016 (Microsoft corporation, USA) and IBM SPSS (Statistical Package for Social Sciences) 
version 23 (IBM incorporation, USA) were used for statistical analysis. Continuous data were presented as mean \pm standard deviation, and a comparison between means of study groups was done by using the unpaired student $t$ test. A $p$ value of less than 0.05 was considered significant.

\section{Results}

The descriptive and clinical data of patients with ALS are presented in Table 1.

In Table 2, the $\mathrm{F}$ wave minimum, maximum, mean latency, chronodispersion, and duration; F/M maximum, mean, and median amplitude ratio; the index repeating neuron; index repeater F wave; and giant $\mathrm{F}$ waves are significantly increased in patients versus controls. On the contrary, $\mathrm{F}$ persistence; $\mathrm{F}$ maximum, mean, and median amplitude; and FWCV were significantly reduced in patients with ALS when compared to the control group.

Table 1 Descriptive and clinical characteristics of patients with ALS

\begin{tabular}{|c|c|}
\hline Characteristics & \\
\hline Age (years) & $54.5(28-70)$ \\
\hline \multicolumn{2}{|l|}{ Sex } \\
\hline Females & $11(50 \%)$ \\
\hline Males & $11(50 \%)$ \\
\hline Disease duration (months) & $15.3(6-24)$ \\
\hline \multicolumn{2}{|l|}{ Disease onset } \\
\hline Bulbar-onset & $11(50 \%)$ \\
\hline Limb-onset & $11(50 \%)$ \\
\hline \multicolumn{2}{|l|}{ El Escorial criteria } \\
\hline Definite ALS & $15(68 \%)$ \\
\hline Probable ALS & $7(32 \%)$ \\
\hline \multicolumn{2}{|l|}{ MRC scale of ADM muscle } \\
\hline Grade 3 & $3(13.5 \%)$ \\
\hline Grade 4 & $16(73 \%)$ \\
\hline Grade 5 & $3(13.5 \%)$ \\
\hline \multicolumn{2}{|l|}{ MRC scale of APB muscle } \\
\hline Grade 2 & $1(4.5 \%)$ \\
\hline Grade 3 & $18(81.9 \%)$ \\
\hline Grade 4 & $3(13.6 \%)$ \\
\hline \multicolumn{2}{|l|}{ MRC scale of FDI muscle } \\
\hline Grade 2 & $3(13.6 \%)$ \\
\hline Grade 3 & $17(77.3 \%)$ \\
\hline Grade 4 & $2(9.1 \%)$ \\
\hline ALSFRS score & $41.5(36-45)$ \\
\hline
\end{tabular}

The data are presented in number and percent except for sex, disease duration, and ALSFRS-R

$A L S$ amyotrophic sclerosis, MRC medical research council, $A D M$ abductor digiti minimi, APB abductor pollicis brevis, FDI first dorsal interosseous, ALSFRS-R amyotrophic sclerosis functional rating scale
Likewise, the APB/ADM amplitude ratio and SHI were markedly reduced in the patient group as compared to the control group.

Patients with ALS were divided into those with (12 patients, 24 hands) and those without (10 patients, 20 hands) pyramidal signs in the upper extremities. The $\mathrm{F}$ mean, median, and maximum amplitude and F/M mean, median, and maximum amplitude ratio were significantly higher in those with pyramidal signs as compared to those without pyramidal signs (Table 3).

When testing the ulnar nerve conduction parameters in patients with ALS, a non-significant difference was demonstrated between those with and without pyramidal signs (Table 4).

Also, patients with ALS were divided according to disease onset into bulbar-onset (11 patients) and limbonset (11 patients). The CMAP amplitude was significantly reduced to a greater degree in patients with limbonset disease as opposed to those with bulbar-onset disease presentation whether it was recorded from APB, FDI, or ADM muscles. Moreover, the APB/ADM amplitude ratio and SHI were significantly lower in patients with limb-onset versus those with bulbar-onset presentation (Table 5).

Table 6 illustrates the comparison between the control group (22 patients, 44 hands) and seven out of 11 patients with limb-onset ALS (14 hands) who are clinically presented without pyramidal signs and muscle wasting. For the APB muscles, the F minimum, mean, and maximum latency; mean FM; index repeater neuron; and index $\mathrm{F}$ repeater were significantly higher whereas the $\mathrm{F}$ persistence and $\mathrm{F}$ mean amplitude were significantly lower in the patient group. For the ADM muscle, only the $\mathrm{F}$ persistence was significantly increased in the patient's group.

Furthermore, neither the CMAP amplitude recorded from $\mathrm{APB}$ or $\mathrm{ADM}$ nor the $\mathrm{APB} / \mathrm{ADM}$ ratio and $\mathrm{FDI} /$ $\mathrm{ADM}$ ratio was different between the two groups.

\section{Discussion}

In our study, different $\mathrm{F}$ wave parameters were significantly different from the control values, such as prolonged $\mathrm{F}$ wave latencies, increased chronodispersion, F/ $\mathrm{M}$ amplitude ratio, and giant $\mathrm{F}$ waves, whereas the $\mathrm{F}$ persistence, $\mathrm{F}$ amplitude, and $\mathrm{F}$ wave $\mathrm{CV}$ were not. On the contrary, other parameters ( $\mathrm{F}$ wave persistence, latency, and duration and also the $\mathrm{F}$ chronodispersion) were comparable between ALS and aged-matched control group. Similar findings were observed by many researchers [16-18]. These discordant findings might result from the difference in sample size or the series of electrical stimuli to elicit $\mathrm{F}$ waves.

The generation of $\mathrm{F}$ waves is affected by a balance between excitatory and inhibitory postsynaptic potentials 
Table 2 F wave parameters and split hand index in patients with ALS and controls

\begin{tabular}{|c|c|c|c|}
\hline Parameter & Controls $n=22$ & ALS patients $n=22$ & $P$ value \\
\hline F min. latency (ms) & $25.37 \pm 2.17$ & $28.19 \pm 1.53$ & $<0.001$ \\
\hline F mean latency (ms) & $26.95 \pm 2.21$ & $29.74 \pm 2.24$ & $<0.001$ \\
\hline F max. latency (ms) & $28.18 \pm 2.48$ & $32.33 \pm 2.39$ & $<0.001$ \\
\hline F chronodispersion (ms) & $2.8 \pm 0.78$ & $4.13 \pm 1.75$ & 0.002 \\
\hline F persistence (\%) & $99.0 \pm 1.93$ & $85.42 \pm 16.98$ & $<0.001$ \\
\hline F max. amplitude $(\mu \mathrm{V})$ & $700.45 \pm 187.98$ & $673.85 \pm 230.85$ & 0.0267 \\
\hline F mean amplitude $(\mu \mathrm{V})$ & $552.44 \pm 156.44$ & $475.47 \pm 209.26$ & 0.018 \\
\hline F median amplitude $(\mu \mathrm{V})$ & $651.3 \pm 176.35$ & $507.46 \pm 193.53$ & 0.004 \\
\hline F wave duration (ms) & $9.41 \pm 1.01$ & $10.39 \pm 1.28$ & 0.001 \\
\hline $\mathrm{FWCV}(\mathrm{m} / \mathrm{s})$ & $63.5 \pm 3.74$ & $57.08 \pm 6.40$ & $<0.001$ \\
\hline Giant F wave $(n)$ & $0.0 \pm 0.0$ & $1.5 \pm 3.08$ & 0.001 \\
\hline F/M Max AR (\%) & $5.24 \pm 1.08$ & $8.11 \pm 1.71$ & $<0.001$ \\
\hline F/M mean AR (\%) & $4.18 \pm 0.76$ & $5.37 \pm 2.11$ & 0.034 \\
\hline F/M median AR (\%) & $4.76 \pm 0.65$ & $7.33 \pm 4.78$ & 0.006 \\
\hline IRN (\%) & $0.0 \pm 0.0$ & $6.87 \pm 16.77$ & $<0.001$ \\
\hline IRF & $0.0 \pm 0.0$ & $4.659 \pm 10.12$ & $<0.001$ \\
\hline \multicolumn{4}{|l|}{ CMAP amplitude (mV) } \\
\hline APB muscle & $11.9 \pm 2.09$ & $6.17 \pm 2.27$ & $<0.001$ \\
\hline ADM muscle & $12.52 \pm 2.05$ & $9.62 \pm 1.67$ & $<0.001$ \\
\hline FDI muscle & $9.97 \pm 1.02$ & $5.09 \pm 0.95$ & $<0.001$ \\
\hline ABP/ADM amplitude ratio & $1.21 \pm 0.33$ & $1.03 \pm 0.51$ & 0.001 \\
\hline FDI/ADM amplitude ratio & $1.31 \pm 0.49$ & $1.29 \pm 0.66$ & 0.609 \\
\hline Split hand index & $15.35 \pm 5.36$ & $10.28 \pm 6.82$ & 0.004 \\
\hline
\end{tabular}

$A L S$ amyotrophic lateral sclerosis, min minimum, max maximum, FWCV F wave conduction velocity, $A R$ amplitude ratio, IRN index repeating neuron, IRF index repeater $\mathrm{F}$ wave, $C M A P$ compound muscle action potential, $A P B$ abductor pollicis brevis, $A D M$ abductor digit minimi, $F D I$ first dorsal interosseous

Table $3 \mathrm{~F}$ wave parameters recorded from ADM muscle in patients with ALS with and without pyramidal signs

\begin{tabular}{|c|c|c|c|}
\hline \multirow[t]{2}{*}{ Parameter } & \multicolumn{2}{|c|}{ Pyramidal signs in patients with ALS } & \multirow[t]{2}{*}{$P$ value } \\
\hline & No $n=24$ & Yes $n=20$ & \\
\hline F min latency (ms) & $28.27 \pm 1.62$ & $28.13 \pm 1.48$ & 0.74 \\
\hline F mean latency $(\mathrm{ms})$ & $29.09 \pm 1.48$ & $30.28 \pm 2.63$ & 0.207 \\
\hline F max latency (ms) & $32.48 \pm 2.16$ & $32.21 \pm 2.61$ & 0.547 \\
\hline F chronodispersion (ms) & $4.16 \pm 1.46$ & $4.1 \pm 1.98$ & 0.777 \\
\hline F persistence $(\%)$ & $87.58 \pm 15.92$ & $83.62 \pm 17.94$ & 0.379 \\
\hline F max amplitude $(\mu \mathrm{V})$ & $591.36 \pm 189.18$ & $742.6 \pm 243.34$ & 0.015 \\
\hline F mean amplitude $(\mu \mathrm{V})$ & $386.81 \pm 119.62$ & $549.35 \pm 239.83$ & 0.013 \\
\hline F median amplitude $(\mu \mathrm{V})$ & $438.65 \pm 169.3$ & $564.8 \pm 196.96$ & 0.029 \\
\hline F wave duration (ms) & $10.1 \pm 0.91$ & $10.63 \pm 1.5$ & 0.150 \\
\hline FWCV (m/s) & $57.23 \pm 4.58$ & $56.95 \pm 7.69$ & 0.333 \\
\hline Giant F wave (n) & $1.4 \pm 3.03$ & $1.58 \pm 3.17$ & 0.111 \\
\hline F/M Max AR (\%) & $7.21 \pm 1.1$ & $8.87 \pm 1.78$ & $<0.001$ \\
\hline F/M mean AR (\%) & $4.35 \pm 1.26$ & $6.22 \pm 2.3$ & 0.012 \\
\hline F/M median AR (\%) & $6.5 \pm 2.8$ & $8.3 \pm 6.3$ & 0.045 \\
\hline IRN (\%) & $4.015 \pm 8.678$ & $9.25 \pm 21.22$ & 0.703 \\
\hline IRF & $3.15 \pm 7.036$ & $5.917 \pm 12.12$ & 0.781 \\
\hline
\end{tabular}

$A L S$ amyotrophic lateral sclerosis, min minimum, max maximum, FWCV F wave conduction velocity, $A R$ amplitude ratio, IRN index repeating neuron, IRF index repeater $\mathrm{f}$ wave 
Table 4 Ulnar nerve conduction parameters of patients with amyotrophic sclerosis

\begin{tabular}{llll}
\hline Parameter & Hands of patients with ALS $n=44$ & & $P$ \\
\cline { 2 - 4 } & Without pyramidal signs $n=24$ & With pyramidal signs $n=20$ & value \\
\hline DML (msec) & $2.44 \pm 0.3$ & $2.31 \pm 0.27$ & 0.199 \\
CMAP amplitude $(\mathbf{m V})$ & $9.84 \pm 2.08$ & $9.48 \pm 1.23$ & 0.369 \\
MCV $(\mathbf{m} / \mathbf{s})$ & $56.18 \pm 1.97$ & $57.25 \pm 2.23$ & 0.101 \\
SNAP amplitude $(\boldsymbol{\mu V})$ & $37.25 \pm 10.9$ & $33.87 \pm 7.49$ & 0.447 \\
SNCV $(\mathbf{m} / \mathbf{s})$ & $58.36 \pm 0.73$ & $58.50 \pm 0.86$ & 0.285 \\
\hline
\end{tabular}

$A L S$ amyotrophic lateral sclerosis, DML distal motor latency, CMAP compound muscle action potential, MCV motor conduction velocity, SNAP sensory nerve action potential, SNCV sensory nerve conduction velocity

on spinal motoneurons. Accordingly, what changes the F wave can be related to the hyperexcitability state which accompanies ALS; the pathophysiological abnormalities after damaging the descending motor pathways, motoneurons, and interneurons in the spinal cord result in increased excitation of remaining functional motoneurons [19].

A lower CMAP amplitude was recorded from thenar and hypothenar muscles in patients with ALS which represents the loss of motor neurons with disease progression $[20,21]$.

A reduced $\mathrm{APB} / \mathrm{ADM}$ ratio and $\mathrm{SHI}$ were observed in patients with ALS which demonstrates a clear difference in dysfunction between the spinal motoneurons and corticomotoneuronal innervating the $\mathrm{APB}$ and $\mathrm{ADM}$ in ALS disease particularly in limb-onset disease, though the mechanisms underlying this disproportionate wasting of hand muscles are yet unclear.

The mean, median, and maximum $\mathrm{F}$ amplitudes were significantly higher in patients with pyramidal signs. This could be due to a more frequent discharge of the responding neurons which produces F responses; an increased number of large motor units (MUs) resulted from axonal sprouting during the process of compensatory reinnervation, also, to the LMN damage in the process of ALS [22, 23].

Table 5 The CMAP amplitude and split hand index in limbonset versus bulbar-onset patients with ALS

\begin{tabular}{|c|c|c|c|}
\hline \multirow[t]{2}{*}{ Parameter } & \multicolumn{2}{|c|}{ Disease onset in patients with ALS $n=22$} & \multirow[t]{2}{*}{$P$ value } \\
\hline & Limb-onset $n=11$ & Bulbar-onset $n=11$ & \\
\hline \multicolumn{4}{|c|}{ CMAP amplitude (mV) } \\
\hline APB muscle & $5.41 \pm 1.73$ & $6.94 \pm 2.51$ & 0.003 \\
\hline ADM muscle & $8.38 \pm 1.22$ & $10.86 \pm 1.0$ & $<0.001$ \\
\hline FDI muscle & $4.44 \pm 0.73$ & $5.75 \pm 0.63$ & $<0.001$ \\
\hline ABP/ADM ratio & $0.96 \pm 0.49$ & $1.27 \pm 0.45$ & 0.039 \\
\hline FDI/ADM ratio & $1.14 \pm 0.56$ & $1.29 \pm 0.43$ & 0.349 \\
\hline Split hand index & $7.8 \pm 3.71$ & $11.42 \pm 4.5$ & 0.048 \\
\hline
\end{tabular}

$A L S$ amyotrophic sclerosis, CMAP compound muscle action potential, $A P B$ abductor pollicis brevis, $A D M$ abductor digiti minimi, $F D I$ first dorsal interosseous
Also, F/M maximum, mean, and median amplitude ratio was higher in patients with pyramidal signs which could result from an increased tendency of motoneurons to produce $\mathrm{F}$ waves. This finding was in agreement with the results reported by other researchers [24, 25].

Clinically, the severity of the LMN sign in patients with ALS with pyramidal signs was not more than those without pyramidal signs. It is worth noting that F/M amplitude ratio may be increased in neuropathies or patients with LMN signs, especially those associated with axonal injury and the resultant decrease in $M$ wave amplitude which made the F/M amplitude ratio not as accurate as absolute F wave amplitude [24]. Nevertheless, in our study there is no significant difference in the ulnar CMAP amplitude between those with and without pyramidal signs. Accordingly, the increased F wave amplitude and F/M amplitude ratio indicated a higher level of segmental motoneuronal excitability [26].

$\mathrm{F}$ wave repeater was not different between patients with and without pyramidal signs. This emphasizes that repeater $\mathrm{F}$ waves would differentiate between health and disease and not within different types of pathologies of the motor neurons or their axons [27]. Fang and colleagues reported differences in repeater $\mathrm{F}$ wave between those with and without pyramidal signs. This could be attributed to the difference in the sample size (152 versus 44), an unequal number of stimulation (100 versus 50) in the current study, or to the low frequency of backfiring resulted from the loss of motoneurons [9].

We found no differences in the F wave latency, chronodispersion, and duration between the two groups. This may be due to the possibility of increased excitability of the motoneuron to produce a larger $\mathrm{H}$ reflex and prevent the slow conducting motoneurons from participating in $\mathrm{F}$ wave activity or loss of fast-conducting, largecaliber $\alpha$-motoneurons in ALS [28, 29].

Also, we noticed no differences in $\mathrm{F}$ wave persistence between pyramidal and nonpyramidal groups; this would support that $\mathrm{F}$ wave persistence was related to the number of functional LMNs and indicates LMN damage.

Moreover, the number of giant $\mathrm{F}$ waves (which may reflect an increase in the MU size during the 
Table $6 \mathrm{~F}$ wave parameters in limb-onset of patients with ALS without pyramidal signs and hand muscle wasting and controls

\begin{tabular}{|c|c|c|c|}
\hline & Patients with ALS $n=14$ & Controls $n=44$ & $P$ value \\
\hline \multicolumn{4}{|l|}{ Parameter/ABP muscle } \\
\hline F minimum latency (ms) & $26.91 \pm 2.28$ & $24.48 \pm 1.65$ & $<0.001$ \\
\hline $\mathrm{F}$ mean latency (ms) & $29.08 \pm 1.57$ & $26.16 \pm 1.39$ & $<0.001$ \\
\hline F maximum latency (ms) & $32.13 \pm 2.42$ & $27.7 \pm 1.93$ & $<0.001$ \\
\hline F persistence (\%) & $78.43 \pm 16.26$ & $96.89 \pm 5.57$ & 0.042 \\
\hline F mean amplitude $(\mu \mathrm{V})$ & $546.21 \pm 287.93$ & $741.8 \pm 153.03$ & $<0.001$ \\
\hline Mean FM & $7.36 \pm 5.61$ & $4.43 \pm 0.77$ & 0.03 \\
\hline Index repeater neuron & $16.93 \pm 29.17$ & $0.00 \pm 0.00$ & $<0.001$ \\
\hline Index F repeater & $13.21 \pm 22.77$ & $0.00 \pm 0.00$ & $<0.001$ \\
\hline \multicolumn{4}{|l|}{ Parameter/ADM muscle } \\
\hline F minimum latency (ms) & $25.2 \pm 1.12$ & $25.38 \pm 2.09$ & 0.76 \\
\hline $\mathrm{F}$ mean latency (ms) & $26.81 \pm 0.8$ & $26.41 \pm 4.26$ & 0.731 \\
\hline $\mathrm{F}$ maximum latency (ms) & $29.99 \pm 2.48$ & $28.77 \pm 2.45$ & 0.19 \\
\hline F mean amplitude $(\mu \mathrm{V})$ & $591.07 \pm 88.84$ & $553.89 \pm 152.97$ & 0.393 \\
\hline F persistence (\%) & $93.14 \pm 8.03$ & $97.27 \pm 5.75$ & 0.039 \\
\hline Mean FM & $4.07 \pm 1.09$ & $4.05 \pm 0.93$ & 0.06 \\
\hline Index repeater neuron & $0 \pm 0.01$ & $0 \pm 0$ & 0.076 \\
\hline Index F repeater & $0 \pm 0.01$ & $0 \pm 0$ & 0.076 \\
\hline ADM CMAP amplitude (mV) & $11.36 \pm 2.25$ & $11.52 \pm 2.05$ & 0.08 \\
\hline APB CMAP amplitude ( $\mathrm{mV}$ ) & $11.68 \pm 1.96$ & $11.93 \pm 2.09$ & 0.968 \\
\hline APB/ADM ratio & $1.06 \pm 0.49$ & $1.19 \pm 0.33$ & 0.244 \\
\hline FDI/ADM Ratio & $1.406 \pm 0.9581$ & $1.305 \pm 0.4889$ & 0.604 \\
\hline
\end{tabular}

ALS amyotrophic lateral sclerosis, $A D M$ abductor digiti minimi, $A P B$ abductor pollicis brevis, $F D /$ first dorsal interosseous, $D M L$ distal motor latency, $C M A P$ compound muscle action potentials, MCV motor conduction velocity, $n$ number of muscles

reinnervation process) was not different between patients with and without pyramidal signs. In general, some pathological characteristics in ALS, for example, changes in distal axon caliber, proximal axonal swellings, and ongoing Wallerian degeneration along axons, may cause dispersion of the efferent volley, resulting in a nonsynchronous muscle response, and this potential functional abnormality would make detection of changes of $\mathrm{F}$ waves difficult [30].

Limb-onset presented patients demonstrate reduced CMAP amplitude recorded from APB, FDI or ADM muscles, $\mathrm{APB} / \mathrm{ADM}$ ratio, and the SHI. This underlies a different pattern of disease progression [31]. On the other hand, FDI/ADM ratio was not different between limb-onset and bulbar-onset ALS patients significantly. This is because thenar muscles receive more extensive corticospinal connections, so they might be vulnerable to glutamate-mediated excitotoxicity than $\mathrm{ADM}$ in the first degree and FDI in the second degree.

From the physiologic point of view, the significant difference in the $\mathrm{F}$ wave persistence and the number of repeater $F$ waves between the APB and ADM may be tied up with a lower number of functional motoneurons innervating the APB [32].
Analyzing F waves, especially of the median nerve, might help in exposing the hidden alterations of anterior horn cells and would be another way for evaluating disease progression. The cortical, peripheral axonal, or spinal segmental dysfunction mechanisms, especially in spinal inhibitory circuits, might contribute to the preferential degeneration of spinal motoneurons innervating the APB muscle [33, 34].

Muscle atrophy may lead to a weaker muscle response by partially neutralizing the hyperexcitability of the motoneuron [26]. ALS patients with limb-onset but with no pyramidal signs and intrinsic hand muscle wasting demonstrated different $F$ wave parameters from the APB muscle and $\mathrm{F}$ persistence from ADM muscle compared with normal controls. Meanwhile, there is no significant difference concerning ADM muscle apart from F persistence. These results were also reported by other research groups $[22,35,36]$. These findings seem to be a result of LMN damage that innervating the APB muscle, formation of large motor units (after reinnervation) in the ADM muscle compared with the APB muscle, and the slower loss in the ADM motoneuron [37].

The significant increase in the number of repeater $F$ waves recorded from APB muscle may imply the proposed mechanisms underlying repeater $F$ waves which 
include increased excitability in particular anterior horn cells, decreased excitability in some motoneurons, or motoneuron loss [9]. These data are coherent with a preferential dysfunction of spinal motoneurons innervating the APB muscle in ALS [36].

The significantly increased F/M amplitude ratio in the APB muscle compared with ADM muscle was also seen by other researchers [37]. It reflects an increased tendency of the motoneurons innervating the APB muscle to produce $\mathrm{F}$ waves. The decreased mean $\mathrm{F}$ wave amplitude and the increased F/M amplitude ratio in the APB muscle confirm the preferential dysfunction of the APB muscle in ALS.

Furthermore, the same subgroup demonstrates no difference regarding the CMAP amplitude of ADM and $\mathrm{APB}$ muscles, $\mathrm{APB} / \mathrm{ADM}$, and FDI/DM ratios. In ALS, the denervation may start earlier and progress faster in the thenar than hypothenar region, the spinal motoneurons innervating the APB muscle may be more active than the ADM muscle, and the CMAP amplitude may not have enough sensitivity for disclosing motoneuron loss because of the reinnervation processes [38].

Among the limitations in our study is the sample size which was relatively small, and it is a convenience sample so findings are not generalizable. We recommend to study the changes in the $\mathrm{F}$ wave response following UMN dysfunction with disease progression and/or response to treatment, also to study the SHI in the early stages of the disease process (or possible category) where the effectiveness of future neuroprotective agents may be at their peak.

In conclusion, $\mathrm{F}$ wave is suitable as an indicator of changes in the segmental motoneuronal excitability following UMN dysfunction in patients with ALS, the SHI could be used as a diagnostic biomarker for ALS and may facilitate the diagnosis, $\mathrm{F}$ wave characteristics are different between the APB and ADM muscles within patients with ALS, and F wave could be of value to discriminate patients with ALS, more than the APB/ADM CMAP amplitude ratio.

\section{Abbreviations \\ ADM: Abductor digiti minimi; ALS: Amyotrophic lateral sclerosis; ALS-FRS: ALS functional rating scale; APB: Abductor pollicis brevis; CMAP: Compound muscle action potentials; DML: Distal motor latency; FDI: First dorsal interosseous; LMN: Lower motor neurons; MNCS: Motor nerve conduction study; MRC: Medical Research Council; MU: Moto unit; NCS: Nerve conduction studies; SHI: Spilt hand index; SNCS: Sensory nerve conduction study; UMN: Upper motor neuron}

\section{Acknowledgements}

We thank assistant professor Dr. Haider F. Ghazi (College of Medicine, AlNahrain University) for doing the statistical analysis.

\section{Authors' contributions}

Concept-N.H.M. and F.B.H; Design-N.H.M. and F.B.H; Supervision-F.B.H.; Resources-A.M.A.; Materials_-N.H.M. and A.M.A.; Data collection and/or processing-N.H.M.; Analysis and/or interpretation-N.H.M. and F.B.H;
Literature Search—N.H.M. and F.B.H; Writing the manuscript—F.B.H. The authors read and approved the final manuscript.

Funding

Self-funding

\section{Availability of data and materials}

All data generated or analyzed during this study are included in this published article. The datasets used and/or analyzed during the current study are available from the corresponding author on reasonable request.

Ethics approval and consent to participate

The study was approved by the Iraqi Council of Medical Specialization (Date 20 March 2019, decision number 1257). All the participants were notified about the technique and aim of the study, and informed consent was obtained from them.

\section{Consent for publication}

Not applicable

\section{Competing interests}

The authors declare that they have no competing interest.

\section{Author details}

'Neurophysiology Unit, Marjan Teaching Hospital, Babel Health Directorate, Babel, Iraq. ${ }^{2}$ Department of Physiology, College of Medicine, Al-Nahrain University, Baghdad, Iraq. ${ }^{3}$ Neurophysiology Unit, Al-Immamain

Al-Kadhimiyain Medical City, Al-Kadhimiya, St. 60, Baghdad, Iraq. ${ }^{4}$ Iraqi Board for Medical Specialization, Baghdad, Iraq

Received: 29 April 2020 Accepted: 8 June 2020

Published online: 17 June 2020

\section{References}

1. Eisen A, Braak H, Del Tredici K, Lemon R, Ludolph AC, Kiernan MC. Cortical influences drive amyotrophic lateral sclerosis. J Neurol Neurosurg Psychiatry. 2017:88:917-24.

2. Wang ZL, Cui L, Liu M, Zhang K, Liu S, Ding Q. Split-hand syndrome in amyotrophic lateral sclerosis: differences in dysfunction of the FDI and ADM spinal motoneurons. Front Neurosci. 2019;13:371

3. Eisen A, Kuwabara S. The split hand syndrome in amyotrophic lateral sclerosis. J Neurol Neurosurg Psychiatry. 2012;83:399-403.

4. Komata T. A case of amyotrophic lateral sclerosis which was diagnosed with progressive dysphagia and muscle atrophy. J Gen Fam Med. 2019;20:25-7.

5. Menon P, Kiernan MC, Vucic S. Appearance, phenomenology and diagnostic utility of the split hand in amyotrophic lateral sclerosis. Neurodegener Dis Manag. 2011;1:457-62.

6. Menon P, Kiernan MC, Yiannikas C, Stroud J, Vucic S. Split-hand index for the diagnosis of amyotrophic lateral sclerosis. Clin Neurophysiol. 2013;124: 410-6.

7. Fisher MA. F-waves--physiology and clinical uses. Sci World J. 2007;7:144-60.

8. Katirji B. Specialized electrodiagnostic studies. In: Electromyography in clinical practice: a case study approach. $2^{\text {nd }}$ edn. Philadelphia: Mosby Inc. USA. 2007; p. 37.

9. Fang J, Cui LY, Liu MS, Guan YZ, Li XG, Cui B, et al. F wave study in amyotrophic lateral sclerosis: assessment of segmental motoneuronal dysfunction. Chin Med J (Engl). 2015;128:1738-42.

10. Lin JZ, Floeter MK. Do F-wave measurements detect changes in motor neuron excitability? Muscle Nerve. 2004:30:289-94.

11. Braun N, Macklin EA, Sinani E, Sherman A, Weber M, the Pooled Resource OpenAccess ALS Clinical Trials Consortium. The revised El Escorial criteria "clinically probable laboratory supported ALS" - once a promising now a superfluous category? Amyotroph Lat Scler Frontotemporal Deg. 2020;21:24-8.

12. Statland JM, Barohn RJ, McVey AL, Katz J, Dimachkie MM. Patterns of weakness, classification of motor neuron disease and clinical diagnosis of sporadic ALS. Neurol Clin. 2015:33:735-48.

13. McDermott CJ. Stay at home with the amyotrophic lateral sclerosis functional rating scale. J Neurol Neurosurg Psychiatry. 2019;91:7.

14. Ciesla N, Dinglas V, Fan E, Kho M, Kuramoto J, Needham D. Manual muscle testing: a method of measuring extremity muscle strength applied to critically ill patients. J Vis Exp. 2011;50:2632. 
15. Preston DC, Shapiro BE. Basic nerve conduction study. In: Electromyography and Neuromuscular Disorders: Clinical-Electrophysiologic Correlations. Chapter 3, 3rd (Eds.). New York: Elsevier Inc.; 2013. p. 19-24.

16. Argyriou AA, Karanasios P, Makridou A, Makris N. F-wave characteristics as surrogate markers of spasticity in patients with secondary progressive multiple sclerosis. J Clin Neurophysiol. 2010;27:120-5.

17. Fang J, Cui L, Liu M, Guan Y, Li X, Li D, et al. Differences in F-wave characteristics between spinobulbar muscular atrophy and amyotrophic lateral sclerosis. Front Aging Neurosci. 2016;8:50.

18. Akarsu EO, Sirin NG, Orhan EK, Erbas B, Dede HO, Baslo MB, et al. Repeater Fwaves in amyotrophic lateral sclerosis: electrophysiologic indicators of upper or lower motor neuron involvement? Clin Neurophysiol. 2020;131:96-105.

19. Swash M. Why are upper motor neuron signs difficult to elicit in amyotrophic lateral sclerosis? J Neurol Neurosurg Psychiatry. 2012;83:659-62.

20. Makino T, Watanabe C, Kumano R, Higaki M, Toji H. Peripheral nerve conduction abnormalities in amyotrophic lateral sclerosis. Neuromuscular Disord. 2014;24:909-10

21. Ren YT, Cui F, Yang F, Chen ZH, Ling L, Huang XS. An analysis of characteristics of nerve conduction in 154 cases of amyotrophic lateral sclerosis. Zhonghua Nei Ke Za Zhi. 2016;55:755-8.

22. Mesrati F, Vecchierini MF. F-waves: neurophysiology and clinical value. Neurophysiol Clin. 2004;34:217-43.

23. Thomas CK, Häger CK, Klein CS. Increases in human motoneuron excitability after cervical spinal cord injury depend on the level of injury. J Neurophysiol. 2017;117:684-91.

24. Fisher MA. F/M ratios in polyneuropathy and spastic hyperreflexia. Muscle Nerve. 1988;11:217-22.

25. Udby Blicher J, Nielsen JF. Evidence of increased motoneuron excitability in stroke patients without clinical spasticity. Neurorehabil Neural Repair. 2009; 23:14-6.

26. Nobrega JA, Manzano GM. A review of technical and physiological aspects of F-wave studies and analysis of the data obtained in a group of diabetic patients. Arq Neuropsiquiatr. 2001;59:192-7.

27. Chroni E, Tendero IS, Punga AR, Stålberg E. Usefulness of assessing repeater F-waves in routine studies. Muscle Nerve. 2012;45:477-85.

28. Espiritu MG, Lin CS, Burke D. Motoneuron excitability and the F wave. Muscle Nerve. 2003:27:720-7.

29. Argyriou AA, Polychronopoulos P, Talelli P, Chroni E. F wave study in amyotrophic lateral sclerosis: assessment of balance between upper and lower motor neuron involvement. Clin Neurophysiol. 2006;117:1260-5.

30. de Carvalho M, Eisen A, Krieger C, Swash M. Motoneuron firing in amyotrophic lateral sclerosis (ALS). Front Hum Neurosci. 2014;8:719.

31. van Damme P, Dewil M, Robberecht W, Van Den Bosch L. Excitotoxicity and amyotrophic lateral sclerosis. Neurodegener Dis. 2005;2:147-59.

32. Gooch CL, Doherty TJ, Chan KM, Bromberg MB, Lewis RA, Stashuk DW, et al. Motor unit number estimation: a technology and literature review. Muscle Nerve. 2014;50:884-93.

33. Do-Ha D, Buskila Y, Ooi L. Impairments in motor neurons, interneurons and astrocytes contribute to hyperexcitability in ALS: underlying mechanisms and paths to therapy. Mol Neurobiol. 2018;55:1410-8.

34. Ramírez-Jarquín UN, Tapia R. Excitatory and inhibitory neuronal circuits in the spinal cord and their role in the control of motor neuron function and degeneration. ACS Chem Neurosci. 2018;9:211-6.

35. Henderson RD, McCombe PA. Assessment of motor units in neuromuscular disease. Neurotherapeutics. 2017;14:69-77

36. Khalaf R, Martin S, Ellis C, Burman R, Sreedharan J, Shaw C, et al. Relative preservation of triceps over biceps strength in upper limb-onset ALS: the 'split elbow'. J Neurol Neurosurg Psychiatry. 2019;90:730-3.

37. Drory VE, Kovach I, Groozman GB. Electrophysiologic evaluation of upper motor neuron involvement in amyotrophic lateral sclerosis. Amyotroph Lat Scler Motor Neuron Disord. 2001:2:147-52

38. van Dijk JP, Schelhaas HJ, van Schaik IN, Janssen HMHA, Stegeman DF, Zwarts MJ. Monitoring disease progression using high-density motor unit number estimation in amyotrophic lateral sclerosis. Muscle Nerve. 2010;42: 239-44

\section{Publisher's Note}

Springer Nature remains neutral with regard to jurisdictional claims in published maps and institutional affiliations.

\section{Submit your manuscript to a SpringerOpen ${ }^{\circ}$ journal and benefit from:}

- Convenient online submission

- Rigorous peer review

- Open access: articles freely available online

High visibility within the field

- Retaining the copyright to your article

Submit your next manuscript at $\boldsymbol{\nabla}$ springeropen.com 